\title{
Combination of vasostatin gene therapy with cyclophosphamide inhibits growth of B16(F10) melanoma tumours
}

\author{
Joanna Jazowiecka-Rakus, Magdalena Jarosz and Stanisław Szala ${ }^{\bowtie}$ \\ Department of Molecular Biology, Maria Skłodowska-Curie Memorial Cancer Center and Institute of Oncology,

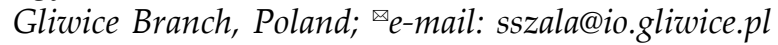

Received: 28 June, 2005; revised: 06 November, 2005; accepted: 04 December, 2005

available on-line: 21 December, 2005

\begin{abstract}
Angiogenesis, i.e. formation of new blood vessels out of pre-existing capillaries, is essential to the development of tumour vasculature. The discovery of specific antiangiogenic inhibitors has important therapeutic implications for the development of novel cancer treatments. Vasostatin, the N-terminal domain of calreticulin, is a potent endogenous inhibitor of angiogenesis and tumour growth. In our study, using B16(F10) murine melanoma model and electroporation we attempted intramuscular transfer of human vasostatin gene. The gene therapy was combined with antiangiogenic drug dosing schedule of a known chemotherapeutic (cyclophosphamide). The combination of vasostatin gene therapy and cyclophosphamide administration improved therapeutic effects in melanoma tumours. We observed both significant inhibition of tumour growth and extended survival of treated mice. To our knowledge, this is one of the first reports showing antitumour efficacy of electroporation-mediated vasostatin gene therapy combined with antiangiogenic chemotherapy.
\end{abstract}

Keywords: angiogenesis, combination, cyclophosphamide, gene therapy, vasostatin

Many endogenous proteins, e.g. thrombospondins, as well as fragments of proteins such as angiostatin, endostatin, antithrombin, tumstatin have been shown to possess antiangiogenic activity (O'Reilly et al., 1997; Prox et al., 2003). The antiangiogenic function of these inhibitors has been well documented in vitro and in vivo; some are currently tested in clinical trials (Folkman, 2003; Eskens, 2004; Ziche et al., 2004).

Vasostatin, the N-terminal domain of calreticulin, is another endogenous inhibitor of angiogenesis and tumour growth (Pike et al., 1998; 1999). The potency of vasostatin in mice is 4-10 fold higher compared with endostatin or angiostatin ( $\mathrm{O}^{\prime}$ Reilly et al., 1997; Cao, 1999). It specifically inhibits endothelial cell attachment to laminin reducing in this way endothelial cell growth induced by basic fibroblast growth factor (Yao et al., 2002). Combination of vasostatin with IL-12 as well as vasostatin and IP-10 (interferon-inducible protein-10) proved effective in reducing growth of human Burkitt lymphoma and human colon carcinoma in murine models (Yao et al., 2000; 2002).

In our study, we decided to test the therapeutic effects of vasostatin gene delivered to skeletal muscles via electroporation and combined cyclophosphamide administration using mice bearing B16(F10) melanoma tumours.

\section{MATERIALS AND METHODS}

Cell culture. B16(F10) murine melanoma cell line (ATCC) was cultured in RPMI 1640 medium supplemented with $10 \%$ foetal bovine serum (ICN Biomedicals, Inc., Aurora, $\mathrm{OH}, \mathrm{USA})$, at $37^{\circ} \mathrm{C}$ and under $5 \% \mathrm{CO}_{2}$.

Animals. Six- to eight-week-old C57BL/6 mice were bred and maintained at the on-site animal facility. Consent for experiments involving animals was obtained from the appropriate Ethics Committee (Medical Academy, Warszawa, Poland).

Abbreviations: bFGF, basic fibroblast growth factor; CTX, cyclophosphamide; IL-12, interleukin-12; IP-10, interferon-inducible protein-10; $\mathrm{PBS}^{-}$, phosphate-buffered saline without $\mathrm{Mg}^{2+}$ and $\mathrm{Ca}^{2+}$. 
Plasmid construction. A DNA fragment encoding vasostatin, the $\mathrm{N}$-terminal domain of human calreticulin (GI: 5921996), was obtained using PCR. To amplify vasostatin, we used as template cDNA derived from human liver total RNA and the following oligonucleotide primers: downstream 5'-AAAAAGGATCCCGAGCCCGCCGTCTAC-3' and upstream 5'-AAAAAGGATCCT-ATTCCAAGGAGCCGGACTCC-3'. The amplified fragment was cloned into the reading frame of the signal sequence in pSHT vector (Gething \& Sambrook, 1989; Madison \& Bird, 1992). Vasostatin fragment with signal sequence was subcloned into expression vectors pVR1012 (Hartikka et al., 1996) and pBCMGSNeo (provided by Dr. H. Karasuyama, formerly Basel Institute of Immunology, Switzerland). The nucleotide sequence of the vasostatin insert linked to the signal sequence in these expression vectors was confirmed using the ABI PRISM Dye Terminator sequencing kit (PE Applied Biosystems, Foster City, CA, USA).

Western blot analysis. Conditioned media from B16(F10) cells stably transfected with pBCMG$\mathrm{SNeo}$ or $\mathrm{pBCMGSNeo/vasostatin}$ were concentrated about 100 -fold and desalted with PBS $^{-}$using the Ultrafree-4 centrifugal filter device 5000 MWCO (Millipore, Bedford, MA, USA). Protein concentration was determined using a protein micro-assay procedure (Bio-Rad, Hercules, CA, USA). Samples of concentrated media were electrophoresed in $15 \%$ polyacrylamide/SDS and transferred onto nitrocellulose membrane (Schleicher \& Schuell, Dassel, Germany). The blot was incubated with goat anti-N-terminal calreticulin (vasostatin) antibody. On the following day, blots were incubated with anti-goat IgG-biotin conjugate (Sigma, St. Louis, MO, USA). The blots were incubated with streptavidin and biotinylated horseradish peroxidase complex (Amersham, Aylesbury, UK). As peroxidase substrate for band staining 3,3'-diaminobenzidine tetrahydrochloride (Sigma) was used.

In vivo angiogenesis assay. Neovascularisation inhibition assay in Matrigel was performed as described (Chen et al., 1999), with slight modifications. Mice (C57BL/6, 4-week-old, three mice per group) were injected s.c. into the midabdominal region with either Matrigel (Becton Dickinson, Bedford, MA, USA) /bFGF (R\&D System, Minneapolis, $\mathrm{MN}, \mathrm{USA})(10 \mu \mathrm{g} / \mathrm{ml})$ plus media conditioned by B16(F10) cells stably transfected with empty pBCMGSNeo vector or $\mathrm{pBCMGSNeo/vasostatin} \mathrm{vector}$ containing $40 \mu \mathrm{g}$ of protein (total injection volume $0.3 \mathrm{ml}$ ). Seven days later Matrigel plugs were removed. The haemoglobin content in the plugs was measured using Drabkin's method and normalised by weight of Matrigel. Each group consisted of three Matrigel plugs.
B16(F10) tumours. C57BL/6 mice had their dorsal side shaved and were inoculated subcutaneously with $2 \times 10^{5}$ B16(F10) melanoma cells in $100 \mu \mathrm{l}$ of $\mathrm{PBS}^{-}$per animal.

Combination of vasostatin gene and cyclophosphamide in B16(F10) melanoma therapy. Therapy was initiated on the third day after inoculation of B16(F10) melanoma cells. First, mice from the control group (pVR1012) and therapeutic groups (pVR1012/vasostatin and pVR1012/vasostatin + CTX) received hyaluronidase ( 20 units/ $25 \mu \mathrm{l}$ of $\mathrm{NaCl}$ ) into both hind limb tibial muscles (Gollins et al., 2003). After one hour mice were injected with the pVR1012/ vasostatin plasmid or empty pVR1012 plasmid at 10 $\mu \mathrm{g} / 100 \mu \mathrm{l}$ of PBS$^{-}$into both hind limb tibial muscles. Following each injection, the muscles were electroporated (electroporation conditions: 5 impulses, 900 $\mathrm{V}, 100 \mu \mathrm{s}$, distance between caliper electrodes $5 \mathrm{~mm}$ ) (Cichon et al., 2002). Such deliveries of DNA by electroporation were repeated four times every six days. On the sixth day of experiment, mice from the therapeutic group (pVR1012/vasostatin + CTX) and the positive control group (CTX only) received i.p. 170 $\mathrm{mg} / \mathrm{kg}$ of cyclophosphamide per dose (four times every six days) (Browder et al., 2000). Eleven mice were used for each treatment or control group.

Statistical analysis. Mann-Whitney $U$-test was used to assess the statistical significance of differential findings. Mouse survival was analysed using Kaplan-Meier survival plot followed by a log-rank test, accepting $P<0.05$ as statistically significant.

\section{RESULTS AND DISCUSSION}

A number of studies have demonstrated that antiangiogenic gene therapy-based approach is effective in reducing tumour growth in animal models. However, gene therapy alone does not guarantee that treatment will be successful. Effects of monotherapy were visible only during continued treatment (Blezinger et al., 1999; Chen et al., 2000; Xiao et al., 2002). Therefore, combining different therapeutic modalities could indeed provide a more efficient strategy for treating solid tumours (Burke \& DeNardo, 2001).

In our study we inserted a PCR-amplified cDNA encoding vasostatin into pBCMGSNeo and pVR1012 expression vectors. The pBCMGSNeo expression vector was used to obtain a stably transfected vasostatin-secreting cell clone. The presence of full-length vasostatin in medium conditioned for $24 \mathrm{~h}$ by a vasostatin-transfected B16(F10) cell clone was detected by Western immunoblotting. There was cross-reaction with the endogenous calreticulin in all samples (Fig. 1). 


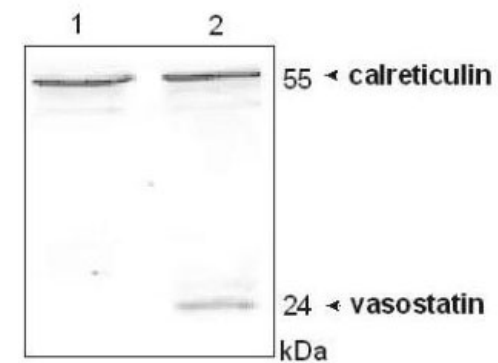

Figure 1. Western blot identification of vasostatin secreted by stably transfected B16(F10) cells.

Concentrated media conditioned by transfected B16(F10)/ pBCMGSNeo clone (lane 1), B16(F10)/pBCMGSNeo/vasostatin clone (lane 2) were electrophoresed and immunoblotted with polyclonal goat antibodies against human calreticulin.

Matrigel assay was used to evaluate in vivo the antiangiogenic effects of vasostatin. Detection of haemoglobin content in the Matrigel plug indicated formation of a functional vasculature within the plug (Chen et al., 1999). Our results show that vasostatin secreted into the medium, derived from pBCMGSNeo/vasostatin-transfected B16(F10) cultures reduces the number of blood vessels by $50 \%$, as compared to control (Fig. 2). This proves that vasostatin is capable of inhibiting endothelial cell growth in vivo.

Tumours derived from the vasostatin-secreting cell clone grew more slowly in vivo than tumours derived from the cell clone transfected with empty pBCMGSNeo vector and, compared to controls, a statistically significant extension of survival was observed (Fig. 3).

For therapeutic experiments, pVR1012 was used because its elements were optimised for in vivo transfection (Hartikka et al., 1996). Vasostatin-encoding plasmid pVR1012 (10 $\mu \mathrm{g} / 100 \mu \mathrm{l}$ of PBS $\left.^{-}\right)$was injected into both hind limb tibial muscles, followed by electroporation. On days 6, 12, 18 and 24 the mice

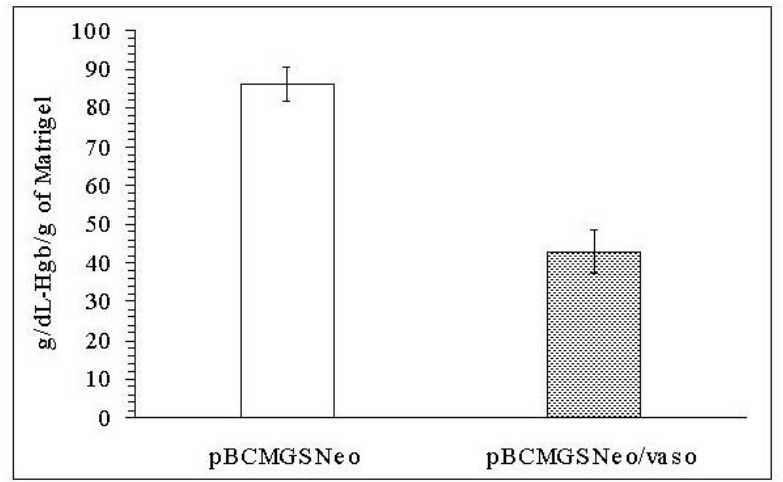

Figure 2. Matrigel plug assay.

Mice were injected with Matrigel as described in Materials and Methods. Seven days later mice were euthanised and Matrigel plugs were removed. Data represent mean haemoglobin content in the Matrigel plug \pm S.D. from groups of three mice. The experiment was performed twice, with similar results. Differences between groups were statistically significant $(P<0.05$, Mann-Whitney $U$-test).

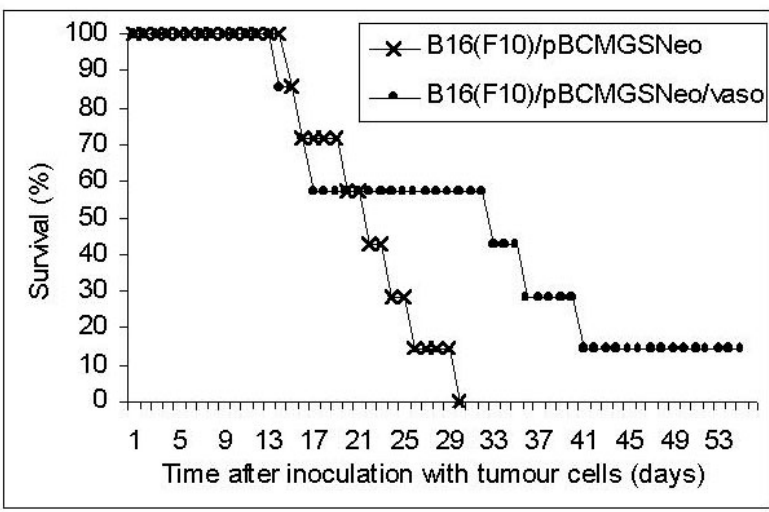

Figure 3. Kaplan-Meier survival curves for B16(F10) cells stably transfected with pBCMGSNeo and pBCMGSNeo/ vasostatin.

Experimental groups consisted of six and seven mice $(P<0.05)$.

received i.p. $170 \mathrm{mg}$ of CTX/kg (Browder et al., 2000). Our data show that intramuscular administration of vasostatin gene (pVR1012/vasostatin) by electroporation had minimal antitumour activity in B16(F10) murine melanoma compared to control mice injected with empty plasmid. Intramuscular delivery of vasostatin gene combined with cyclophosphamide $(p V R 1012 /$ vasostatin + CTX) resulted in more effective inhibition of tumour growth in murine models than that achievable with these agents acting separately (data not shown). Although survival of mice was prolonged after chemotherapy alone, combined therapy extends it more significantly (Fig. 4). We report that combined treatment with vasostatin and

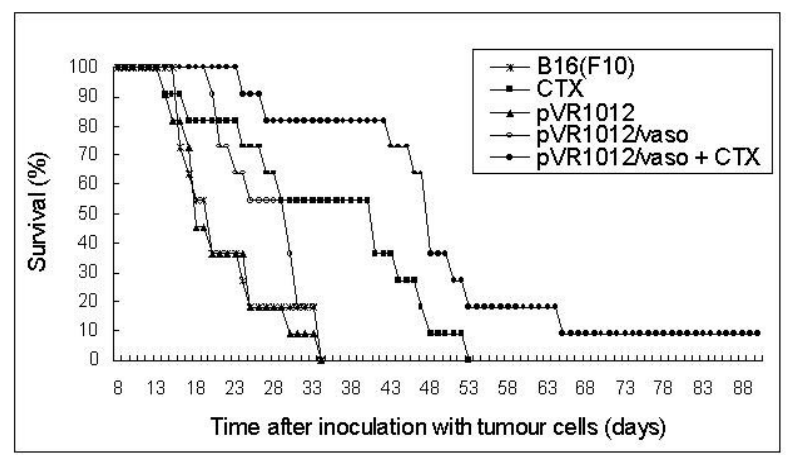

Figure 4. Extension of mice survival following intramuscular injection of pVR1012/vasostatin plasmid constructs, electroporation and cyclophosphamide treatment.

C57Bl6 mice were inoculated subcutaneously with a suspension of B16(F10) cells $\left(2 \times 10^{5}\right.$ cells per mouse). Beginning on the third day after inoculation, mice were injected (each hind limb tibial muscle, four times, every six days) with vasostatin gene construct (pVR1012/vasostatin, $10 \mu \mathrm{g}$ in $100 \mu \mathrm{l}$ of $\mathrm{PBS}^{-}$). Muscles were then electroporated (5 impulses, $900 \mathrm{~V}, 100 \mu \mathrm{s})$. One hour before electroporation, hyaluronidase (20 U/25 $\mu \mathrm{l}$ per each hind leg, i.m.) was injected. Starting on the sixth day of experiment, mice from the therapeutic group (pVR1012/vasostatin + CTX) and positive control group (CTX) began receiving i.p. $170 \mathrm{mg} / \mathrm{kg}$ of CTX (four times every six days). Experimental groups consisted of 11 mice $(P<0.04)$. 
cyclophosphamide shows a trend toward enhanced antitumour efficacy in B16(F10) melanoma-bearing mice.

To conclude, our study using a murine model indicates that cancer gene therapy via intramuscular delivery of plasmid DNA encoding an angiogenesis inhibitor (vasostatin) combined with cyclophosphamide is effective in systemic inhibition of angiogenesis and improves animal survival. However, it seems that alternative strategy combining recombinant vasostatin and CTX can improve therapeutic reliability.

\section{Acknowledgements}

This study was supported by a grant (No. 007/2002) from Polpharma Foundation.

We thank Dr. J. Szary, Ms. H. Paterak and Ms. M. Krawczyk for technical assistance, and Dr. A. Sochanik for reviewing the article.

\section{REFERENCES}

Blezinger P, Wang J, Gondo M, Quezada A, Mehrens D, French M, Singhal A, Sullivan S, Rolland A, Ralston R, Min W (1999) Systemic inhibition of tumor growth and tumor metastases by intramuscular administration of the endostatin gene. Nat Biotechnol 17: 343-348.

Browder T, Butterfield CE, Kraling BM, Shi B, Marshall B, O'Reilly MS, Folkman J (2000) Antiangiogenic scheduling of chemotherapy improves efficacy against experimental drug-resistant cancer. Cancer Res 60: 1878-1886.

Burke PA, DeNardo SJ (2001) Antiangiogenic agents and their promising potential in combined therapy. Crit Rev Oncol Hematol 39: 155-171.

Cao Y (1999) Therapeutic potentials of angiostatin in the treatment of cancer. Haematologica 84: 643-650.

Chen CT, Lin J, Li Q, Phipps SS, Jakubczak JL, Stewart DA, Skripchenko Y, Forry-Schaudies S, Wood J, Schnell C, Hallenbeck PL (2000) Antiangiogenic gene therapy for cancer via systemic administration of adenoviral vectors expressing secretable endostatin. Hum Gene Ther 11: 1983-1996.

Chen QR, Kumar D, Stass SA, Mixson AJ (1999) Liposomes complexed to plasmids encoding angiostatin and endostatin inhibit breast cancer in nude mice. Cancer Res 59: 3308-3312.

Cichon T, Jamrozy L, Glogowska J, Missol-Kolka E, Szala S (2002) Electrotransfer of gene encoding endostatin into normal and neoplastic mouse tissues: inhibition of primary tumor growth and metastatic spread. Cancer Gene Ther 9: 771-777.
Eskens F (2004) Angiogenesis inhibitors in clinical development; where are we now and where are we going? Br J Cancer 12: 1-7.

Folkman J (2003) Angiogenesis and apoptosis. Semin Cancer Biol 13: 159-167.

Gething MJ, Sambrook J (1989) Protein folding and intracellular transport: studies on influenza virus haemagglutinin. Biochem Soc Symp 55: 155-166.

Gollins H, McMahon J, Wells KE, Wells DJ (2003) High-efficiency plasmid gene transfer into dystrophic muscle. Gene Ther 10: 504-512.

Hartikka J, Sawdey M, Cornefert-Jensen F, Margalith M, Barnhart K, Nolasco M, Vahlsing HL, Meek J, Marquet M, Hobart P, Norman J, Manthorpe M (1996) An improved plasmid DNA expression vector for direct injection into skeletal muscle. Hum Gene Ther 7: 1205-1217.

Madison EL, Bird P (1992) A vector, pSHT, for the expression and secretion of protein domains in mammalian cells. Gene 121: 179-180.

O'Reilly MS, Boehm T, Shing Y, Fukai N, Vasios G, Lane WS, Flynn E, Birkhead JR, Olsen BR, Folkman J (1997) Endostatin: an endogenous inhibitor of angiogenesis and tumor growth. Cell 88: 277-285.

Pike SE, Yao L, Jones KD, Cherney B, Appella E, Sakaguchi K, Nakhasi H, Teruya-Feldstein J, Wirth P, Gupta G, Tosato G (1998) Vasostatin, a calreticulin fragment, inhibits angiogenesis and suppresses tumor growth. J Exp Med 188: 2349-2356.

Pike SE, Yao L, Setsuda J, Jones KD, Cherney B, Appella E, Sakaguchi K, Nakhasi H, Atreya CD, Teruya-Feldstein J, Wirth P, Gupta G, Tosato G (1999) Calreticulin and calreticulin fragments are endothelial cell inhibitors that suppress tumor growth. Blood 94: 2461-2468.

Prox D, Becker C, Pirie-Shepherd SR, Celik I, Folkman J, Kisker O (2003) Treatment of human pancreatic cancer in mice with angiogenic inhibitors. World J Surg 27: 405-411.

Xiao F, Wei Y, Yang L, Zhao X, Tian L, Ding Z, Yuan S, Lou Y, Liu F, Wen Y, Li J, Deng H, Kang B, Mao Y, Lei S, He Q, Su J, Lu Y, Niu T, Hou J, Huang MJ (2002) A gene therapy for cancer based on the angiogenesis inhibitor, vasostatin. Gene Ther 9: 1207-1213.

Yao L, Pike SE, Setsuda J, Parekh J, Gupta G, Raffeld M, Jaffe ES, Tosato G (2000) Effective targeting of tumor vasculature by the angiogenesis inhibitors vasostatin and interleukin-12. Blood 96: 1900-1905.

Yao L, Pike SE, Pittaluga S, Cherney B, Gupta G, Jaffe ES, Tosato G (2002a) Anti-tumor activities of the angiogenesis inhibitors interferon-inducible protein-10 and the calreticulin fragment vasostatin. Cancer Immunol Immunother 5: 358-366.

Yao L, Pike SE, Tosato G (2002b) Laminin binding to the calreticulin fragment vasostatin regulates endothelial cell function. J Leukoc Biol 71: 47-53.

Ziche M, Donnini S, Morbidelli L (2004) Development of new drugs in angiogenesis. Curr Drug Targets 5: 485493. 